\title{
Pengaruh Perbedaan Kedalaman Terhadap Fitoplankton dan Zooplankton Di Perairan Pulau Panjang, Jepara
}

\author{
Deftika Mulyawati*, Raden Ario, Ita Riniatsih \\ Departemen IImu Kelautan, Fakultas Perikanan dan IImu Kelautan, Universitas Diponegoro \\ JI. Prof. H. Soedarto S.H, Tembalang,Semarang, Jawa Tengah 50275 Indonesia \\ *Corresponding author, e-mail: deftika.mulyawati@gmail.com
}

\begin{abstract}
ABSTRAK : Plankton merupakan sebuah kelompok organisme yang hanyut bebas di dalam lautan. Plankton dapat dibagi menjadi dua golongan, yaitu fitoplankton dan zooplankton. Penelitian ini bertujuan untuk mengetahui hubungan dari kelimpahan fitoplankton dan zooplankton berdasarkan perbedaan kedalaman di perairan timur Pulau Panjang Kabupaten Jepara. Pengambilan sampel dilakukan dengan metode aktif yaitu dengan menarik plankton net dengan mata jaring ukuran $45 \mu$ untuk fitoplankton dan $150 \mu$ untuk zooplankton. Penarikan dilakukan menggunakan kapal selama 3-5 menit dengan kecepatan kapal 0,67 m/s pada lokasi penelitian. Penentuan stasiun penelitian berdasarkan pada perbedaan kedalaman. Kedalaman air laut yang digunakan pada saat pengambilan sampel ini adalah stasiun 1 dengan kedalaman $0 \mathrm{~m}$ atau permukaan air laut, stasiun 2 dengan kedalaman 1-2 m dari permukaan air laut, dan stasiun 3 dengan kedalaman 3-4 m dari permukaan air laut. Pengukuran kualitas perairan dilakukan secara in situ bersamaan dengan pengambilan sampel dilakukan. Hasil dari penelitian ini didapatkan komposisi fitoplankton sebanyak 13 genus dengan kelimpahan berkisar antara 3844,19-10869,80 individu $/ \mathrm{m}^{3}$. Komposisi zooplankton di perairan didapatkan sebanyak 12 genus dengan kelimpahan berkisar antara 838,77-3250,24 individu/ $\mathrm{m}^{3}$. Hubungan kelimpahan antara zooplankton dan fitoplankton di perairan ini termasuk kedalam golongan hubungan korelasi positif
\end{abstract}

Kata Kunci : Fitoplankton, Zooplankton, Kelimpahan

\section{The Effect of Depth Difference on Phytoplankton and Zooplankton in Pulau Panjang Waters, Jepara}

ABSTRACT : Plankton is a group that drifts freely in the ocean. Plankton has limited mobility. Plankton can be divided into two groups, namely phytoplankton and zooplankton. This study aims to determine the relationship of the abundance of phytoplankton and zooplankton based on rates in the east of Panjang Island, Jepara Regency. Sampling is done by the active method, namely by pulling the plankton net with a mesh size of $45 \mu$ for phytoplankton and $150 \mu$ for zooplankton. Withdrawals carried out by a ship for 3-5 minutes with a ship speed of $0.67 \mathrm{~m} / \mathrm{s}$ at the study site. Determination of research stations based on differences in depth. The depth of sea water used during sampling is station 1 with a depth of $0 \mathrm{~m}$ or sea level, station 2 with a depth of 1-2 $\mathrm{m}$ from sea level, and station 3 with a depth of 3-4 m above sea level. Measurements of water quality were carried out in situ together with sampling. The results of this study obtained phytoplankton compositions as many as 13 genera with abundance ranging from 3844.19-10869.80 individuals $/ \mathrm{m}^{3}$. The composition of zooplankton in the waters obtained as many as 12 genera with abundance ranging from 838.77-3250.24 individuals $/ \mathrm{m}^{3}$. The relationship of abundance between zooplankton and phytoplankton in these waters is included in the group of positive correlation.

Keywords: Phytoplankton, Zooplankton, Abundance

\section{PENDAHULUAN}

Perairan pesisir Jepara merupakan daerah intertidal, daerah itu merupakan zona dangkal yang terletak di antara garis pasang naik dan pasang surut. Zona ini memiliki faktor fisik maupun faktor kimia yang mendukung semua organisme didalamnya untuk dapat tumbuh dan berkembang. Zona intertidal adalah daerah pantai yang terletak antara pasang tinggi dan surut terendah, daerah ini mewakili peralihan dari kondisi lautan ke kondisi daratan (Aji et al., 2014). 
Plankton merupakan kelompok organisme yang hidup melayang di perairan dan pergerakannya dipengaruhi oleh arus. Plankton dapat dibagi menjadi dua golongan, yaitu fitoplankton dan zooplankton, dan berdasarkan daur hidupnya dapat dibagi menjadi dua golongan, yaitu golongan holoplankton dan golongan meroplankton. Golongan holoplankton merupakan golongan yang seluruh daur hidupnya bersifat planktonik, sedangkan golongan meroplankton merupakan golongan yang sebagian daur hidupnya bersifat planktonik (Nybakken, 1998).

Distribusi plankton di perairan bervariasi berdasarkan kedalaman, hal ini cenderung dipengaruhi oleh jumlah cahaya yang diterima oleh fitoplankton untuk kegiatan fotosintesis yang akan dilakukannya. Secara temporal intensitas cahaya matahari yang jatuh di permukaan laut akan terdistribusi mengikuti kedalaman dan menyebabkan variabilitas intensitas cahaya matahari di kolom perairan. Perbedaan ini menyebabkan kelimpahan fitoplankton, produser utama zat organik dalam rantai makanan, juga bervariasi di setiap kedalaman. Karena peran utamanya sebagai produser utama dalam rantai makanan maka fitoplankton digunakan sebagai indikator utama tingkat kesuburan perairan (Siregar et al., 2014). Penelitian ini dilakukan untuk mengetahui kelimpahan dari fitoplankton dan zooplankton berdasarkan kedalaman yang berbeda dan mengetahui hubungan antara kelimpahan fitoplankton dan zooplankton di perairan timur Pulau Panjang Kabupaten Jepara.

\section{MATERI DAN METODE}

Penelitian ini dilakukan pada bulan April hingga Mei 2018 di perairan timur Pulau Panjang Kabupaten Jepara. Materi pada penelitian ini berupa data kelimpahan fitoplankton dan zooplankton di perairan timur Pulau Panjang Kabupaten Jepara. Data pendukung yang diambil antara lain data kualitas perairan berupa data fisika kimia perairan yang diukur secara in situ.

Metode penentuan lokasi penelitian yang digunakan adalah metode purposive sampling method dimana metode ini digunakan untuk mengambil sampel dengan tujuan tertentu. Penelitian ini penentuan lokasi diambil berdasarkan atas perbedaan kedalaman yang terdapat di perairan pantai Pulau Panjang Kabupaten Jepara. Kedalaman laut yang digunakan pada penelitian ini antara lain Stasiun 1 dengan kedalaman $0 \mathrm{~m}$ atau permukaan air laut, Stasiun 2 dengan kedalaman 1-2 m dari permukaan air laut, dan Stasiun 3 dengan kedalaman 3-4 m dari permukaan air laut (Rosada et al., 2017). Metode yang digunakan untuk pengambilan sampel menggunakan metode aktiv yaitu penarikan jaring plankton menggunakan kapal. Identifikasi sampel dilakukan di Laboratorium Biologi Fakultas Perikanan dan IImu Kelautan Universitas Diponegoro dengan metode langsung menggunakan sedwick rafter dan mikroskop yang berpedoman pada buku identifikasi plankton Yamaji (1966).

Kelimpahan plankton dapat dihitung dengan menggunakan rumus (APHA, 2005). Keanekaragaman Plankton pada setiap stasiun dapat dihitung menggunakan rumus dari Shannonwienner (Odum, 1998). Keseragaman yang terdapat pada setiap stasiun dapat dihitung dengan menggunakan indeks keseragaman Eveness (Siregar, 2014). Indeks keseragaman ini menggunakan kriteria $\mathrm{E}<0,4$ : Keseragaman rendah; $0,4<\mathrm{E}<0,6$ : Keseragaman sedang; $\mathrm{E}>0,6$ : Keseragaman tinggi. Indeks dominansi dihitung dengan menggunakan rumus dari Odum (1998).

Uji analisis hubungan yang digunakan pada penelitian ini menggunakan analisa regresi linear sederhana dan uji korelasi dengan menggunakan aplikasi Microsoft Office Excel 2010. Menurut Siregar (2014) Uji analisis hubungan dengan menggunakan uji korelasi adalah suatu pengujian yang menggunakan metode statistik untuk melihat hubungan antara 2 variabel atau lebih. Apabila terdapat kenaikan satu variabel dan diikuti oleh kenaikan variabel lain maka dapat dikatakan bahwa kedua variabel tersebut memiliki hubungan korelasi yang positif, akan tetapi jika kenaikan di dalam suatu variabel tidak diikuti atau bahkan terjadi penurunan pada variabel lainnya maka dapat dikatakan hubungan kedua variabel tersebut negatif. 


\section{HASIL DAN PEMBAHASAN}

Hasil penelitian yang dilakukan di perairan timur Pulau Panjang Kabupaten Jepara teridentifikasi sebanyak 4 kelas dengan 12 genus fitoplankton antara lain Chaetoceros, Nitzchia, Thalassiosira, Skeletonema, Hemiaulus, Biddulphia, Chrococus, Ceratium, Nocticula, Peridinium, Coscinodiscus, dan Rhizosolenia dengan kelimpahan paling banyak terdapat pada genus Chaetoceros sp. dari kelas Bacillariophyceae. Menurut Sari et al. (2014), banyaknya jenis fitoplankton yang terdapat dari kelas Bacillariophyceae ini dikarenakan kelas Bacillariophyceae lebih mampu beradaptasi dengan kondisi lingkungan yang ada, kelas ini bersifat kosmopolitan serta mempunyai toleransi dan daya adaptasi yang tinggi.

Kelimpahan zooplankton selama penelitian pada perairan timur Pulau Panjang Kabupaten Jepara didapatkan 4 kelas dengan 12 genus zooplankton yaitu antara lain Copepoda, Lucifer, Cyclops, Acartia, Haloptilus. Calanus, Centropager, Eucalanus, Euchaeta, Acrocalanus, Paracalanus, dan Mesodinium. Kelimpahan paling banyak terdapat pada genus Malacostraca. Menurut Sari et al. (2014), bahwa Malacostraca merupakan zooplankton yang memiliki adaptasi yang baik, dapat tumbuh dan berkembang dengan baik hanya pada lingkungan yang cocok. Golongan zooplankton yang sangat penting dan mendominasi perairan laut yaitu subkelas Copepoda yang termasuk dalam filum Arthropoda.

Kelimpahan fitoplankton dan zooplankton yang didapatkan selama penelitian dapat dilihat pada Gambar 1. Kelimpahan fitoplankton dan zooplankton selama penelitian.

\section{Indeks Keanekaragaman, Indeks Dominansi, dan Indeks Keseragaman Fitoplankton dan Zooplankton}

Nilai rata-rata Indeks Keanekaragaman, Indeks Dominansi, dan Indeks Keseragaman Fitoplankton dan Zooplankton yang didapat selama penelitian dapat dilihat pada Tabel 1, Tabel 2, dan Tabel 3. Komunitas fitoplankton dan zooplankton yang terdapat pada perairan timur Pulau Panjang Kabupaten Jepara termasuk ke dalam komunitas sedang. Menurut Ridwan et al. (2016) menyatakan bahwa keanekaragaman yang berada pada $1<H^{\prime}<3$ termasuk kedalam golongan keanekaragaman sedang. Indeks keseragaman fitoplankton dan zooplankton yang terdapat di perairan timur Pulau Panjang Kabupaten Jepara termasuk ke dalam kategori keseragaman yang tinggi. Menurut Utojo (2008) indeks keseragaman yang mendekati nilai nol (0) cenderung menunjukan komunitas yang tidak stabil, sedangkan jika mendekati nilai satu (1) maka komunitas dalam keadaan stabil, jumlah individu antar jenis sama. Indeks dominansi fitoplankton dan zooplankton yang terdapat pada perairan timur Pulau Panjang Kabupaten Jepara termasuk kedalam golongan dominansi yang rendah. Menurut Liwutang et al. (2013), jika suatu ekosistem memiliki nilai keanekaragaman yang tinggi atau sedang maka dominasinya tergolong rendah. Inasafitri (2010) menyatakan semakin besar nilai indeks dominansi (D) maka semakin besar pula kecenderungan adanya jenis tertentu yang mendominansi.

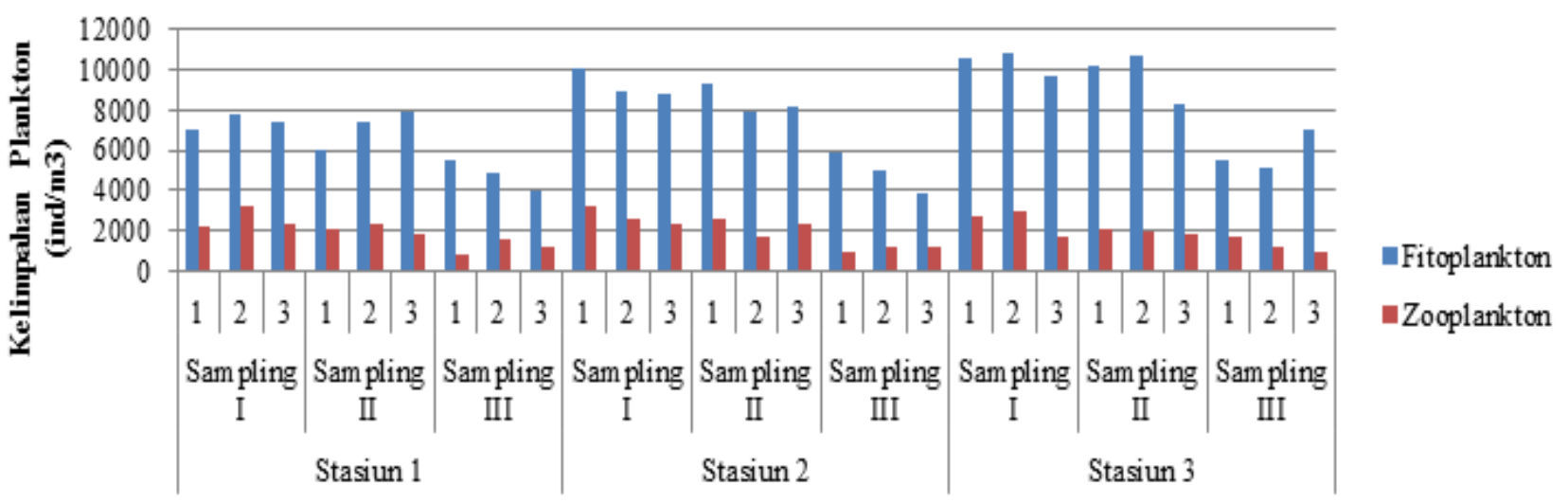

Lokasi Pengambilan Data

Gambar 1. Kelimpahan Fitoplankton dan Zooplankton pada saat Penelitian 


\section{Hubungan Kelimpahan Fitoplankton dan Zooplankton}

Hubungan antara kelimpahan fitoplankton dan zooplankton membutuhkan nilai data kelimpahan fitoplankton dan zooplankton. Identifikasi hubungan kelimpahan ini didasarkan pada nilai korelasi Spearman antar kelimpahan fitoplankton dengan zooplankton. Korelasi Spearman adalah alat uji statistik yang digunakan untuk menguji dugaan tentang adanya hubungan antara variabel.

Hubungan kelimpahan fitoplankton dan zooplankton pada stasiun 1 dapat dilihat pada Gambar 2. Hubungan fitoplankton dan zooplankton memiliki nilai korelasi Spearman sebesar 0,5437 dengan indeks determinasi sebesar 0,2957. Nilai korelasi Spearman yang didapatkan untuk fitoplankton dapat diartikan bahwa kelimpahan fitoplankton di perairan memiliki pengaruh sebesar $29,5 \%$. Nilai kelimpahan tersebut menunjukkan jenis korelasi untuk fitoplankton termasuk dalam kategori tinggi karena fitoplankton berada pada perairan dengan kriteria fisika dan kimia perairan yang tepat untuk tumbuh dan berkembang.

Hubungan kelimpahan antara fitoplankton dan zooplankton pada stasiun 2 ditunjukan pada Gambar 3. Hubungan ini memiliki korelasi linier yang positif. Nilai korelasi Spearman untuk fitoplankton sebesar 0,0806 dan indeks determinasi sebesar 0,0065. Nilai korelasi Spearman tersebut dapat diartikan bahwa kelimpahan fitoplankton memiliki pengaruh sebesar $0,65 \%$ dengan indeks determinasi yang tergolong dalam korelasi kelimpahan yang rendah.

Hubungan antara kelimpahan fitoplankton dan zooplankton yang terdapat pada stasiun 3 ditunjukan pada Gambar 4. Hubungan ini memiliki korelasi linier yang negatif. Nilai korelasi Spearman untuk fitoplankton sebesar 0,395 dan indeks determinasi sebesar 0,1563. Nilai korelasi Spearman dapat diartikan bahwa fitoplankton memegang pengaruh terhadap perairan sebesar $15,6 \%$ dengan indeks determinasi tergolong dalam korelasi rendah.

Kualitas perairan yang didapat selama penelitian secara lengkap dapat dilihat pada Tabel 4. Kecepatan arus selama penelitian berlangsung berkisar antara $5-15 \mathrm{~cm} / \mathrm{s}$, dengan kecerahan berkisar 3,0 - 3,5 meter yang artinya perairan ini memiliki kecerahan yang cukup jernih. Substrat dasar yang terdapat pada perairan ini didominasi substrat pasir. Nilai kandungan kimia perairan yang terdapat di perairan Pulau Panjang Kabupaten Jepara memiliki nilai kandungan nitrat

Tabel 1. Rata-rata Indeks Keanekaragaman Plankton selama Penelitian

\begin{tabular}{cccccccccc}
\hline \multirow{2}{*}{ Sampling } & \multicolumn{3}{c}{ Stasiun 1 } & \multicolumn{3}{c}{ Stasiun 2 } & \multicolumn{3}{c}{ Stasiun 3 } \\
\cline { 2 - 10 } & 1 & 2 & 3 & 1 & 2 & 3 & 1 & 2 & 3 \\
\hline Fitoplankton & 1,81 & 1,96 & 1,92 & 1,78 & 1,89 & 1,91 & 1,73 & 1,64 & 1,61 \\
Zooplankton & 2,12 & 2,24 & 2,05 & 2,01 & 2,20 & 2,01 & 1,65 & 1,74 & 1,63 \\
\hline
\end{tabular}

Tabel 2. Rata-rata Indeks Keseragaman Plankton selama Penelitian

\begin{tabular}{lrrrrrrrrr}
\hline \multirow{2}{*}{ Sampling } & \multicolumn{3}{c}{ Stasiun 1 } & \multicolumn{3}{c}{ Stasiun 2 } & \multicolumn{3}{c}{ Stasiun 3 } \\
\cline { 2 - 10 } & 1 & 2 & 3 & 1 & 2 & 3 & 1 & 2 & 3 \\
\hline Fitoplankton & 0,87 & 0,95 & 0,93 & 0,86 & 0,91 & 0,92 & 0,84 & 0,79 & 0,78 \\
Zooplankton & 0,89 & 0,94 & 0,86 & 0,85 & 0,93 & 0,85 & 0,69 & 0,73 & 0,69 \\
\hline
\end{tabular}

Tabel 3. Rata-rata Indeks Dominansi Plankton selama Penelitian

\begin{tabular}{lrrrrrrrrr}
\hline \multirow{2}{*}{ Sampling } & \multicolumn{3}{c}{ Stasiun 1 } & \multicolumn{3}{c}{ Stasiun 2 } & \multicolumn{3}{c}{ Stasiun 3 } \\
\cline { 2 - 10 } & 1 & 2 & 3 & 1 & 2 & 3 & 1 & 2 & 3 \\
\hline Fitoplankton & 0,18 & 0,17 & 0,18 & 0,21 & 0,18 & 0,19 & 0,21 & 0,23 & 0,25 \\
Zooplankton & 0,15 & 0,12 & 0,15 & 0,16 & 0,12 & 0,16 & 0,22 & 0,19 & 0,24 \\
\hline
\end{tabular}


berkisar 0,068-0,5605 mg/L. dan nilai kandungan fosfat berkisar 0,0228-0,1770 mg/L. Kecepatan angin saat penelitian didapatkan nilai berkisar antara $0,185-0,275 \mathrm{~m} / \mathrm{s}$. Kondisi cuaca yang cerah selama penelitian berlangsung dan tidak terjadi hujan, menjadi faktor pendukung yang dialami selama proses penelitian dan pengambilan data berlangsung.

Rendahnya nilai pada korelasi ini dapat dikarenakan faktor fisika dan kimia perairan pada perairan tersebut. Salah satu parameter yang mempengaruhi nilai korelasi ini adalah salinitas perairan. Nilai rata-rata salinitas yang di dapat selama penelitan sebesar $28,6 \%$ o. Nilai ini tidak termasuk ke dalam nilai salinitas yang sesuai untuk perkembangan plankton karena menurut Keputusan Menteri Lingkungan Hidup No. 51/MENLH/2004 nilai salinitas yang optimal untuk pertumbuhan plankton berkisar antara 33-34\%. Sedangkan menurut Nybakken (1998) menyatakan bahwa salinitas yang baik untuk pertumbuhan plankton di laut adalah $30-35 \%$.

Hasil dari Gambar 5 yang didapatkan selama penelitian menunjukan bahwa adanya hubungan antara kelimpahan fitoplankton dan zooplankton. Analisis sederhana yang dilakukan pada grafik hubungan kelimpahan fitoplankton dan zooplankton selama penelitian memiliki hubungan korelasi positif dengan nilai $\mathrm{R}^{2}$ sebesar 0,548 dan korelasi Spearman sebesar 0,746. Nilai ini menunjukan bahwa kelimpahan fitoplankton mempengaruhi kelimpahan dari zooplankton sebesar $54 \%$.

Kelimpahan fitoplankton cenderung dipengaruhi oleh keberadaan cahaya di perairan yang berkaitan dengan waktu pengambilannya. Keberadaan intensitas cahaya akan menurun pada kedalaman yang lebih dalam. Waktu pengambilan sampel yang dilakukan pada penelitian ini adalah pagi hari. Waktu pagi hari ini memungkinkan kelimpahan fitoplankton yang cukup banyak

Tabel 4. Rata - Rata Kualitas Perairan Selama Penelitian

\begin{tabular}{|c|c|c|c|c|c|c|c|c|c|c|}
\hline \multirow{3}{*}{ Parameter } & \multicolumn{9}{|c|}{ Waktu Sampling } & \multirow{3}{*}{$\begin{array}{l}\text { Baku } \\
\text { Mutu }\end{array}$} \\
\hline & \multicolumn{3}{|c|}{ Sampling I } & \multicolumn{3}{|c|}{ Sampling II } & \multicolumn{3}{|c|}{ Sampling III } & \\
\hline & 1 & 2 & 3 & 1 & 2 & 3 & 1 & 2 & 3 & \\
\hline Suhu $\left({ }^{\circ} \mathrm{C}\right)$ & 29,8 & 29 & 28,8 & 28,5 & 28,3 & 28 & 29,2 & 28,9 & 28,5 & $28-30$ \\
\hline Salinitas (\%o) & 28 & 27,8 & 27,6 & 29 & 28,8 & 28,7 & 29,2 & 28,9 & 29,6 & 33-34 \\
\hline Kecerahan ( $\mathrm{m}$ & 3,5 & 3,5 & 3,5 & 3 & 3 & 3 & 3,3 & 3,3 & 3,3 & - \\
\hline & 8,53 & 8,5 & 8,55 & 8,52 & 8,5 & 8,51 & 8,6 & 8,5 & 8,5 & $7-8,5$ \\
\hline $\mathrm{DO}(\mathrm{mg} / \mathrm{L})$ & 6,4 & 6 & 5 & 6,5 & 5,6 & 5,4 & 6,4 & 6,3 & 6,3 & $>5$ \\
\hline
\end{tabular}

Keterangan : 1 = Stasiun 1; 2 = Stasiun 2; 3 = Stasiun 3 Sumber Baku Mutu : KEP MENLH No. 51/MENLH/2004

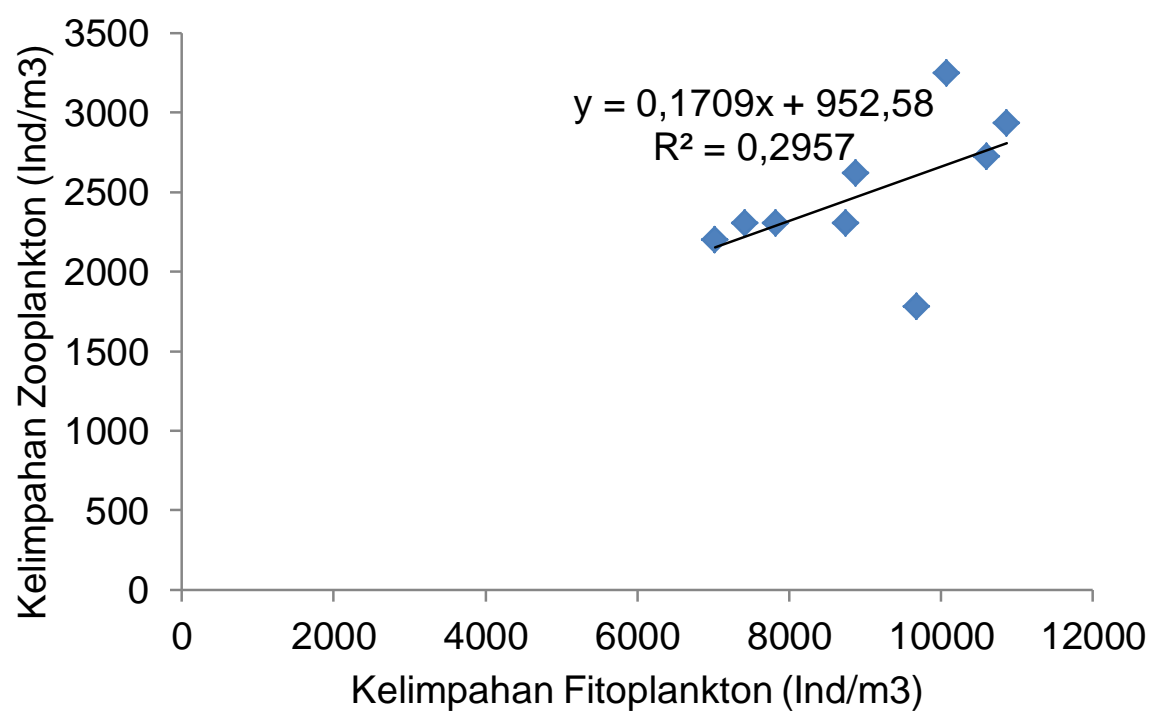

Gambar 2. Hubungan Kelimpahan Fitoplankton dan Zooplankton di Stasiun 1 saat Penelitian 


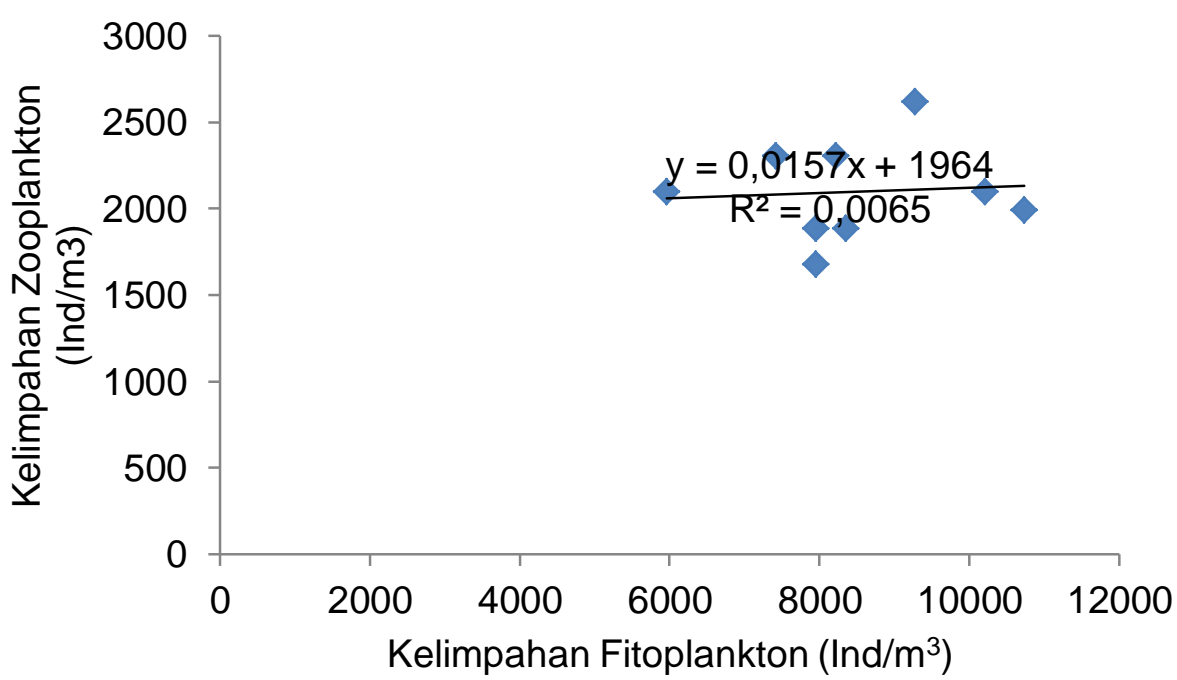

Gambar 3. Hubungan Kelimpahan Fitoplankton dan Zooplankton di Stasiun 2 saat Penelitian

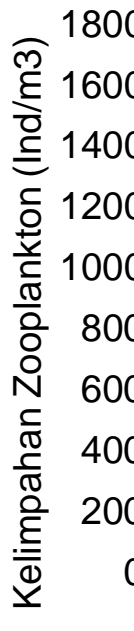

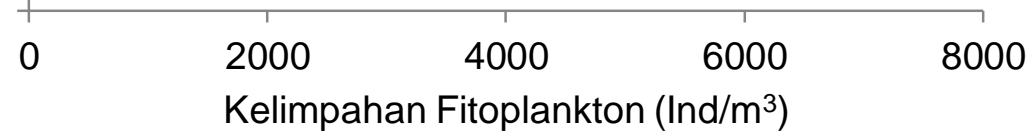

Gambar 4. Hubungan Kelimpahan Fitoplankton dan Zooplankton di Satasiun 3 saat Penelitian

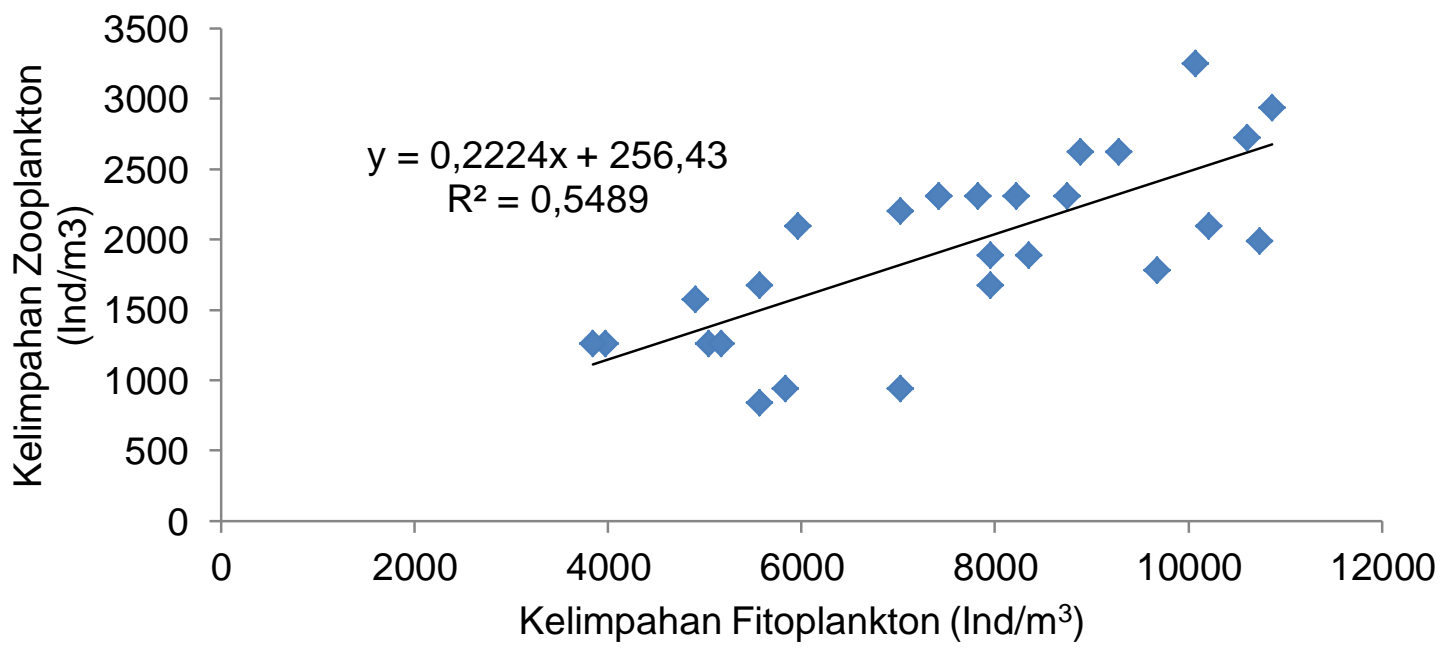

Gambar 5. Hubungan Kelimpahan Fitoplankton dan Zooplankton selama Penelitian 
karena pada pagi hari fitoplankton melakukan aktivitas fotosintesis. Menurut Djokosetiyanto dan Rahardjo (2012), fitoplankton biasanya berkumpul di zona eufotik yaitu zona dengan intensitas cahaya yang masih memungkinkan terjadinya fotosintesis.

Kelimpahan zooplankton yang didapat selama penelitian cenderung lebih sedikit karena adanya proses migrasi vertikal zooplankton. Menurut Pratama et al. (2012), pola perilaku plankton memiliki fenomena migrasi vertikal diurnal yang terjadi akibat berbagai penyebab, salah satunya adalah adanya photoperiod fitoplankton. Menurut Moniharapon et al. (2014), migrasi vertikal zooplankton sangat bergantung kepada respons dan adaptasi organisme ini terhadap perubahan lingkungan misalnya temperatur, salinitas, makanan, oksigen dan predator. Fenomena migrasi vertikal diurnal mempengaruhi komposisi, dominansi, dan keanekaragaman tiap jenis plankton dalam suatu waktu.

\section{KESIMPULAN}

Komposisi plankton yang terdapat pada perairan timur Pulau Panjang Kabupaten Jepara antara lain fitoplankton memiliki 12 genus dan komposisi zooplankton terdiri dari 12 genus. Kelimpahan fitoplankton yang terdapat pada perairan timur Pulau Panjang Kabupaten Jepara berkisar antara nilai 3844,19-10869,80 individu/ $\mathrm{m}^{3}$ sedangkan kelimpahan zooplankton di perairan timur Pulau Panjang Kabupaten Jepara berkisar antara nilai 838,77-3250,24 individu/m³. Hubungan kelimpahan antara fitoplankton dan zooplankton pada ketiga kedalaman memiliki nilai korelasi positif dengan nilai indeks determinasi sebesar 0,548 dan korelasi Spearman sebesar 0,746 .

\section{DAFTAR PUSTAKA}

Aji, W.P. \& Muskananfola, M.R., 2014. Kelimpahan Zooplankton Krustasea Berdasarkan Fase Bulan Di Perairan Pantai Jepara, Kabupaten Jepara. Management of Aquatic Resources Journal, 3(3):188-196.

Utojo, A.M. 2008. Komposisi dan Keragaman Jenis Plankton di Perairan Teluk Kupang Provinsi Nusa Tenggara Timur. Torani,18(2):129-135.

APHA American Public Health Association. 2005. Standard Methods For the Examination of Water and Wastewater. Amer. Publ. 17th Edition. New York Health Association.

Djokosetiyanto, D \& Rahardjo, S. 2012. Kelimpahan dan Keanekaragaman Fitoplankton di Perairan Pantai Dadap Teluk Jakarta. Jurnal IImu-IImu Perairan dan Perikanan Indonesia. 13(2):135-141

Inasafitri. 2010. Keanekaragaman, Keseragaman, Dan Dominansi Bivalvia Di Area Buangan Lumpur Lapindo Muara Sungai Porong . Jurnal Kelautan Universitas Trunojoyo. 3(1):54-59

Liwutang, Y.E., Manginsela, F.B. \& Tamanampo, J. 2013. Kepadatan dan Keanekargaman Fitoplankton di Perairan Sekitar Kawasan Reklamasi Pantai Manado. Jurnal IImiah Platax, $1(3): 109-117$

Moniharapon, D., Jaya, I., Manik, H., Pujiyati, S., Hestirianoto, T. \& Syahailatua, A., 2014. Migrasi vertikal zooplankton di Laut Banda. Jurnal Kelautan Nasional, 9(3), pp.143-149.

Nybakken, J.W. \& Eidman, H.M., 1998. Biologi laut: satu pendekatan ekologis. Gramedia.

Odum Ep. 1998. Dasar-Dasar Ekologi. Edisi Ketiga. Diterjemahkan Oleh T. Samingan. Gadjah Mada University Press. Yogyakarta

Pratama, B.B., Hasan, Z. \& Hamdani, H., 2012. Pola Migrasi Vertikal Diurnal Plankton di Pantai Santolo Kabupaten Garut. Jurnal Perikanan Kelautan, Jurnal Perikanan dan IImu Kelautan. 3(1):81-89

Ridwan, M., Fathoni, R., Fatihah, I., \& Pangestu, D.A. 2016 . Struktur Komunitas Makrozoobenthos di Empat Muara Sungai Cagar Alam Pulau Dua, Serang, Banten . Al-Kauniyah. 9(1): 57-65

Rosada, K.K., Sunardi, P., Kusumaningrum, T.D. \& Putri, S.A. 2017. Struktur Komunitas Fitoplankton pada Berbagai Kedalaman di Pantai Timur Pananjung Pangandaran. Jurnal Biojati. 2(1):30-37 
Sari, A.N., Hutabarat, S. \& Soedarsono, P., 2014. Struktur Komunitas Plankton pada Padang Lamun di Pantai Pulau Panjang, Jepara. Management of Aquatic Resources Journal, 3(2):8291.

Siregar, L.L., Hutabarat, S. \& Muskananfola, M.R., 2014. Distribusi Fitoplankton Berdasarkan Waktu dan Kedalaman yang Berbeda di Perairan Pulau Menjangan Kecil Karimunjawa. Management of Aquatic Resources Journal, 3(4):9-14.

Yamaji, C. S. 1966. Ilustration Of Marine Plankton Japan. Hoikusha Publishing Co. Ltd. Japan. 